\title{
Association between lifestyle factors and suboptimal health status among Chinese college freshmen: a cross-sectional study
}

\author{
Chenjin Ma', Wangli Xu', Long Zhou', Shuangge $\mathrm{Ma}^{2}$ and Yu Wang ${ }^{1 *}$
}

\begin{abstract}
Background: Suboptimal health status (SHS) is the third state between good health and disease. SHS is the clinical or pre-disease status of psychosomatic disease and a major global public health challenge. Although its underlying causes remain unclear, lifestyle is one of the most important factors affecting health status.
\end{abstract}

Methods: A cross-sectional survey was conducted at Renmin University of China in September of 2015. Data were collected from college freshmen using a questionnaire covering characteristics, lifestyle, nutrition status, and health status. A total of 6025 questionnaires were distributed during the study period, and 5344 completed responses were received.

Results: The prevalence rates for the "healthy," "SHS," and "disease" groups of college freshmen were 46.7\% (2433), 51.2\% (2667), and 2.1\% (111), respectively. It is notable that health status was significantly positively correlated with lifestyle (Spearman's $r=0.4435, p<0.001$ ). The multivariate Logistic regression results showed that students who were relatively younger and students from rural areas had a higher percentage of SHS. Good sleep quality $(\mathrm{aOR}=0.650,95 \% \mathrm{Cl}=0.612-0.690)$, abundant physical exercise $(\mathrm{aOR}=0.889,95 \% \mathrm{Cl}=0$. $845-0.933)$, and adequate nutrition intake $(\mathrm{aOR}=0.868,95 \% \mathrm{Cl}=0.864-0.908)$ are negatively associated with SHS. Overuse of electronic devices $(\mathrm{aOR}=1.066,95 \% \mathrm{Cl}=1.013-1.121)$, smoking $(\mathrm{aOR}=1.824,95 \% \mathrm{Cl}=1.195-2$. $755)$, and weight loss (aOR $=1.255,95 \% \mathrm{Cl}=1.043-1.509)$ are positively associated with SHS.

Conclusions: Poor lifestyle behaviors are associated with SHS. In particular, the overuse of electronic devices is one of underlying causes of SHS. By altering lifestyle behaviors for the better, the health statuses of these college freshmen can be effectively improved.

Keywords: Suboptimal health status, Lifestyle behaviors, Electronic devices, College freshmen, China

\section{Background}

In 1946, the World Health Organization (WHO) defined health as "a state of complete physical, mental, and social well-being and not merely the absence of disease or infirmity" [1,2]. With changes in living environments, especially urbanization, more and more people reported suboptimal health without a diagnosable condition, which is called suboptimal health status (SHS) [3]. SHS is an intermediate state between health and disease, which is often medically undiagnosed. In the traditional Chinese medicine guidelines released by the China Association of Chinese Medicine (CACM), medically undiagnosed or functional somatic syndromes [4-6] are characterized by a decline in vitality, in physiological

\footnotetext{
* Correspondence: abyuer@sina.com

${ }^{1}$ Center for Applied Statistics and School of Statistics, Renmin University of

China, Beijing, China

Full list of author information is available at the end of the article
} 
function, and in the capacity for adaptation [3, 7]. SHS people frequently suffer symptoms, such as headaches, dizziness, chronic fatigue, depression, anxiety, functional system disorders (e.g., disorders of the digestive system, cardiovascular system, urinary system, etc.) and non-specific pain (e.g., back pain and chest pain). Accordingly, SHS sufferers often experienced impaired quality of life, frequent hospital visits, and expensive medical expenses [6,7].

Recent years, many other countries widely accepted the concept of SHS, including Japan, Canada, and Australia [8-10]. Surveys of SHS have involved people of different groups such as teachers, civil servants, businessmen, community residents, medical personnel, and others [3,11-13]. Due to the inconsistent definitions of SHS adopted by these different studies, as well as the different questionnaires or scales used, the reported rates of SHS vary greatly, from 20 to $80 \%$ [3, 10, 14]. In 1998, some researchers conducted a thorough examination of 6000 asymptomatic "healthy people." The results showed that $72.8 \%$ were in the "suboptimal health status" range [15]. The incidence of SHS is high, but its causes are unclear. According to the previous studies, lifestyle behaviors are considered as one of the most important factors affecting health [16-19], and poor lifestyle factors may be associated with SHS, such as work-related and study-related stress, physical inactivity, short sleep time and unhealthy diet patterns $[3,10,14,20,21]$.

Most previous surveys on suboptimal health status have mainly focused on specific populations, such as teachers, civil servants, etc. $[11,15,22]$. Only a few studies have explored SHS among university students, who are generally considered to be a relatively healthy population. Some studies, though, have showed that the rate of SHS in this population is high. One study of 11,144 students in 2013 revealed that the prevalence rate for the SHS group of respondents was $55.9 \%$, and girls experienced a higher rate of SHS than boys [10]. For college students, particularly freshmen, their lifestyle behaviors can undergo great changes during campus life. Most typically, due to heavy study loads and anxiety, many students do not eat regularly, get sufficient sleep, or exercise adequately. As a result, they may suffer from headaches, insomnia, fatigue, and/or forgetfulness. Additionally, according to some global health behavior studies among university students, students had a high proportion of poor health behavior practices, and several health risk behaviors were identified, including overweight, poor dental practices, poor dietary patterns, tobacco use and sleeping habits. [23, 24] One cross-sectional survey of 800 university students in India found that there was a high rate of overweight and obesity and poor dietary patterns. [25] With the development of technology, more and more college students are using electronic devices. Researchers have begun to pay increased attention to the impact of electronic equipment on the health of students. A retrospective, nested, casecontrol study conducted from 2009 to 2011 showed that freshmen exhibiting signs of depression, learning maladaptation, and dissatisfaction could be an important target intervention population for reducing Internet addiction [26]. But no studies to date have focused on the relationship between the usage of electronic products and suboptimal health status. In order to explore the association between various lifestyle factors and suboptimal health status and fill the noted gaps in the research, we conducted a cross-sectional study among college freshmen in China.

\section{Methods \\ Sample and data collection}

A cross-sectional survey was conducted at Renmin University of China during September of 2015. The study sample included all freshmen enrolled in the university in 2015. The data were collected using a self-administered questionnaire. At the beginning of each survey, the interviewer introduced the nature of the survey. Each interviewee was asked to sign an informed consent form. An interviewee was excluded if he/she refused to participate. The questionnaire was completed by each student within $30 \mathrm{~min}$. All data were kept strictly confidential. The study was approved by the ethics committee of Renmin University.

A total of 6025 questionnaires were distributed during the study period, and 5646 (93.7\%) questionnaires were returned. A total of 5233 completed responses were analyzed in this study after a review, yielding a valid response rate of $86.5 \%$.

The questionnaire (see Additional file 1) was composed of four sections: students' characteristics, a health promotion lifestyle scale (HPLS), the Suboptimal Health Measurement ScaleV1.0 (SHMS V1.0), and history of diseases. The sections on students' characteristics, the HPLS, and history of diseases were self-designed according to the questionnaires in other research works [27-32]. The SHMS V1.0 is a standardized questionnaire [33] used to assess respondents' health status, and it contains a multidimensional, self-report symptom inventory developed by a research group in China $[10,21]$. The SHMS V1.0 consists of 39 items in total, 35 of which are divided among three symptom 
Table 1 Structure Framework of the Suboptimal Health Measurement Scale V1.0

\begin{tabular}{lll}
\hline Dimension & Factors & Items \\
\hline Physiological & Physical condition & 3 \\
& Organ function & 6 \\
& Body movement function & 3 \\
& Vigor & 2 \\
Psychological & Positive emotion & 4 \\
& Psychological symptoms & 6 \\
& Cognitive function & 2 \\
Social & Social adjustment & 4 \\
& Social resources & 3 \\
Health self-evaluation & Social support & 2 \\
Total & Physiological/ & 4 \\
\hline
\end{tabular}

dimensions (physiological symptoms: 14 items, psychological symptoms: 12 items, and social symptoms: 9 items), as indicated in Table 1. The remaining four items focus on health self-evaluation. For each item, there are five response categories $(1=$ never, 2 = occasionally, $3=$ sometimes, $4=$ constantly, and $5=$ always).

\section{SHS evaluation}

The evaluation of SHS in this study was performed according to the clinical guidelines for SHS published by the CACM [33]. Participants were asked about uncomfortable symptoms they experienced during the previous six months. The total scores were then calculated. The original score of every factor was equivalent to the total score of items included in this factor, and the original score of every dimension was equivalent to the total score of factors included. The original total score was equal to the sum of the three dimension scores. Then the original raw score was converted to obtain the final score according to the following formula for the conversion of original raw scores in dimension, subscale, and scale into percentile scores. The converted scores were used to analyze the outcomes-that is, the total score of health status, which ranges from $0 \sim 100$. A lower total score represents a lower estimate of SHS.
Before completing the survey, the participating students each underwent a school health examination in a hospital. The health examination included a detailed medical history, a physical examination, blood hematology and biochemistry analyses, rest electrocardiogram, and chest radiography. Students with abnormal results were required to receive a reexamination. A total of 111 students $(2.1 \%)$ were found to be in disease status. We deleted these data of these students in disease status, so the health status in this research was divided into two statuses: healthy and suboptimal health. Taking the unilateral P10 point of all dimensions of a crowd as the criterion, the dividing line scores of the three dimensions of physical suboptimal health, psychological suboptimal health, and social suboptimal health were 66.07, 52.08 , and 55.56, respectively. When the score for any dimension of the three was lower than the dividing line score, it could be judged as suboptimal health status. If participants did not have SHS with respect to any of these three dimensions, they were considered healthy. The reliability of SHMS V1.0 has been confirmed, with a Cronbach's $\alpha$ of 0.679 .

\section{Lifestyle behaviors assessment}

The health promotion lifestyle scale (HPLS) in this questionnaire was created on the basis of the "Health Promoting Lifestyle Profile (HPLP)" developed by Walker et al. [27-29] and the Pittsburgh Sleep Quality Index developed by Buysseet et al. [30-32]. Included were seven dimensions, constituting a total of 26 items: "sleep quality index" (7 items), "physical activity" (4 items), "usage of electronic devices" (3 items), "usage of tobacco" (1 item), "usage of alcohol" (1 item), "nutrition status" (9 items), and "losing weight or not" (1 item). All of these items over a period of the previous six months were investigated.

Sleep quality index (SQI) included sleep quality, sleep latency, sleep duration, and habitual sleep efficiency. Each item in the sleep quality index had scores of zero to three points, and the sum of the items was the total score for the SQI. The total scores ranged from zero to 12. The higher the score, the better a participant's sleep quality. The scores for nutrition status range from $0 \sim 27$, with a lower score representing a poorer nutrition status. The scores for the usage of electronic devices range from zero to 11, with a lower score signaling a less desirable behavior. The scores for "usage of alcohol," "usage of tobacco," and "losing weight or not" are zero or one, with zero representing "does not have this behavior" and one "has this behavior." 


\section{Statistical analysis}

The statistical analysis was conducted using $\mathrm{R}$ software. The variables of normal distribution were described by mean and standard deviation, the variables of abnormal distribution were described by median and quartile, and categorical variables were described by frequency. Pearson $\chi^{2}$ test and $t$ test were used to compare variables, and the corresponding 95\% confidence intervals (CIs) were calculated. $P$-value of $<0.05$ was considered to be significant for all tests. Logistic regression analysis was conducted, and the odds ratios (OR) and their significance levels were computed. All of these analyses were conducted on all of participants' data except for those participants marked as "disease status".

\section{Results}

\section{Students' characteristics}

The prevalence rates for the healthy, SHS, and disease groups of college freshmen were $46.7 \%$ (2433), $51.2 \%$ (2667), and 2.1\% (111), respectively. The characteristics of all participants (except for those in the disease status category) are presented in Table 2. Among the notable characteristics, 3426 (64.3\%) were female, and the mean age was 21.7 years old, ranging from 16 to 45 .

\section{Health promotion lifestyle scale}

Table 3 presents the scores for the HPLS under two health statuses. The results showed that the scores for "sleep quality index," "physical activity," and "nutrition status" among healthy students $(8.58 \pm 1.77,4.79 \pm 2.10$, $18.34 \pm 3.02$, respectively) were significantly higher than the scores among students classified with suboptimal health status $(7.76 \pm 1.86,3.94 \pm 2.16,16.89 \pm 3.28$, respectively). This means that the sleep quality and nutrition status of the healthy students are better than that of the suboptimal health students, and healthy people more actively participate in physical exercise. Also, the score for "use of electronic devices" among healthy students were significantly lower than the scores among students classified with suboptimal health status $(4.30 \pm 1.74$ vs $4.83 \pm 2.03)$. It means suboptimal health people are more likely to be heavy users of electronic devices. It was further found that male students were more likely to be classified with SHS $(P=0.035)$.

Figure 1 is the scatter diagram of the health status scores and health promotion lifestyle scale scores. It is easy to see from the figure that the SHMS V1.0 scores and HPLS scores have a positive correlation. The Pearson correlation coefficient is $0.4435(p<0.001)$.

\section{Multivariate logistic regression analyses of SHS}

The multivariate logistic regression analyses results for SHS are shown in Table 4. Among them, "sleep quality index," "physical activity," "usage of electronic devices,"
Table 2 Characteristics of Participating Students in the Survey $(n=5100)^{a}$

\begin{tabular}{|c|c|}
\hline Participant Characteristics & $\mathrm{n}(\%)$ or mean $\pm \mathrm{SD}$ \\
\hline Age in Years & $21.7 \pm 3.6$ \\
\hline \multicolumn{2}{|l|}{ Age Group (years) } \\
\hline $15-19$ & $2261(44.3)$ \\
\hline $20-24$ & $2164(42.4)$ \\
\hline 25 and above & $675(13.3)$ \\
\hline \multicolumn{2}{|l|}{ Gender } \\
\hline Male & $1768(34.7)$ \\
\hline Female & $3321(65.3)$ \\
\hline \multicolumn{2}{|l|}{ Ethnicity } \\
\hline Han & $4606(90.9)$ \\
\hline Other & $460(9.1)$ \\
\hline \multicolumn{2}{|l|}{ Student Type } \\
\hline Bachelor's candidates & $2253(44.3)$ \\
\hline Master's candidates & $2361(46.4)$ \\
\hline Doctoral candidates & $475(9.3)$ \\
\hline \multicolumn{2}{|l|}{ Area } \\
\hline Rural & $1309(25.9)$ \\
\hline Urban & $3751(74.1)$ \\
\hline Health Status (range from 0-100) & $73.13 \pm 9.47$ \\
\hline Health & $2728(52.4)$ \\
\hline Suboptimal health & $2481(47.6)$ \\
\hline $\begin{array}{l}\text { Physiological Health Status (range from } \\
0-100)\end{array}$ & $78.79 \pm 9.69$ \\
\hline Health & $4586(90.7)$ \\
\hline Suboptimal health & $468(9.2)$ \\
\hline $\begin{array}{l}\text { Psychological Health Status (range from } \\
0-100)\end{array}$ & $67.57 \pm 12.10$ \\
\hline Health & $4640(91.7)$ \\
\hline Suboptimal health & $4422(8.3)$ \\
\hline Social Health Status (range from 0-100) & $71.25 \pm 12.49$ \\
\hline Health & $4417(87.2)$ \\
\hline Suboptimal health & $646(12.8)$ \\
\hline Sleep Quality Index (range from 0 to 12) & $9.75 \pm 1.49$ \\
\hline Physical Activity (range from 0 to 12) & $5.16 \pm 1.92$ \\
\hline $\begin{array}{l}\text { Usage of Electronic Devices (range from } \\
0 \text { to 11) }\end{array}$ & $6.59 \pm 1.86$ \\
\hline Nutrition Status (range from 0-27) & $17.96 \pm 3.16$ \\
\hline \multicolumn{2}{|l|}{ Usage of Tobacco } \\
\hline No & $4895(96.0)$ \\
\hline Yes & $201(4.0)$ \\
\hline \multicolumn{2}{|l|}{ Usage of Alcohol } \\
\hline No & $2820(55.3)$ \\
\hline Yes & $2276(44.7)$ \\
\hline \multicolumn{2}{|l|}{ Losing Weight } \\
\hline No & $2425(47.7)$ \\
\hline Yes & $2663(52.3)$ \\
\hline
\end{tabular}


Table 3 Scores of the Health Promotion Lifestyle Scale Under Two Health Statuses $(n=5100)^{\text {a }}$

\begin{tabular}{|c|c|c|c|}
\hline \multirow[t]{2}{*}{ Characteristics } & \multicolumn{2}{|c|}{ Health Promotion Lifestyle Scale Scores } & \multirow{2}{*}{$\begin{array}{l}P- \\
\text { Value }\end{array}$} \\
\hline & Healthy & SHS & \\
\hline Age Group (years) & & & 0.880 \\
\hline $15-19$ & $1084(48.0 \%)$ & 1175 (52.0\%) & \\
\hline $20-24$ & $1030(47.6 \%)$ & $1134(52.4 \%)$ & \\
\hline 25 and above & $317(47.0 \%)$ & $358(53.0 \%)$ & \\
\hline Gender & & & 0.035 \\
\hline Male & $821(46.4 \%)$ & $947(53.6 \%)$ & \\
\hline Female & $1603(48.3 \%)$ & $1718(51.7 \%)$ & \\
\hline Area & & & $<0.001$ \\
\hline Rural & $706(53.9 \%)$ & $603(46.1 \%)$ & \\
\hline Urban & $1702(45.4 \%)$ & 2049 (54.6\%) & \\
\hline Sleep Quality Index & $8.58 \pm 1.77$ & $7.76 \pm 1.86$ & $<0.001$ \\
\hline Physical Activity & $4.79 \pm 2.10$ & $3.94 \pm 2.16$ & $<0.001$ \\
\hline Usage of Electronic Devices & $4.30 \pm 1.74$ & $4.83 \pm 2.03$ & $<0.001$ \\
\hline Nutrition Status & $18.34 \pm 3.02$ & $16.89 \pm 3.28$ & $<0.001$ \\
\hline Smoking & & & 0.033 \\
\hline No & $2317(47.3 \%)$ & $2578(52.7 \%)$ & \\
\hline Yes & $114(56.7 \%)$ & $87(43.3 \%)$ & \\
\hline Drinking & & & 0.654 \\
\hline No & $1329(47.1 \%)$ & 1491 (52.9\%) & \\
\hline Yes & $1102(48.4 \%)$ & $1174(51.6 \%)$ & \\
\hline Losing Weight or Not & & & 0.060 \\
\hline No & $1196(49.3 \%)$ & $1229(50.7 \%)$ & \\
\hline Yes & $1233(46.3 \%)$ & 1430 (53.7\%) & \\
\hline
\end{tabular}

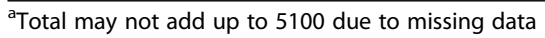

and "nutrition" are quantitative variables, while the rest are qualitative variables. After controlling for age group, gender, and areas, SHS was associated with sleep quality $(\mathrm{aOR}=0.650, \quad 95 \% \mathrm{CI}=0.612-0.690)$, physical activity $(\mathrm{aOR}=0.889,95 \% \mathrm{CI}=0.845-0.933)$, habits of using electronic devices $\quad(\mathrm{aOR}=1.066, \quad 95 \% \mathrm{CI}=1.013-1.121)$, nutrition $(\mathrm{aOR}=0.868,95 \% \mathrm{CI}=0.864-0.908)$, smoking $(\mathrm{aOR}=1.824, \quad 95 \% \mathrm{CI}=1.195-2.755)$ and weight loss $(\mathrm{aOR}=1.255,95 \% \mathrm{CI}=1.043-1.509)$. Students aged 20 24 years old or living in an urban area were more likely to be classified in the healthy status group. The students with lower scores in sleep quality were more likely to be

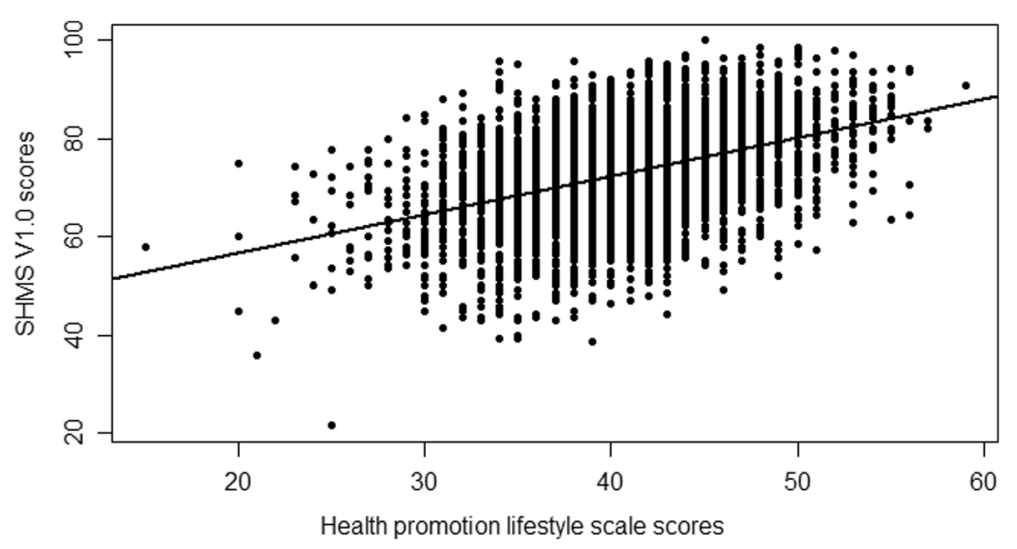

Fig. 1 Scatter Plot of Suboptimal Health Measurement ScaleV1.0 Scores and Health Promotion Lifestyle Scale Scores 
Table 4 Logistic Regression Model for Health-Related Factors and Health Status

\begin{tabular}{lllllll}
\hline Health-Related Factors & Estimate & $P$ & aOR & \multicolumn{2}{c}{$95 \%$ Cl for aOR } \\
\cline { 5 - 7 } & & & & Lower & Upper \\
\hline Gender (male as a control) & & & & & \\
$\quad$ Female & 0.030 & 0.786 & 1.030 & 0.831 & 1.280 \\
Area (rural as a control) & & & & & \\
$\quad$ Urban area & -0.250 & 0.015 & 0.779 & 0.638 & 0.953 \\
Age Group (15-19 as a control) & & & & \\
20-24 & -0.223 & 0.028 & 0.801 & 0.657 & 0.975 \\
25 and above & 0.073 & 0.614 & 1.075 & 0.808 & 1.423 \\
Sleep Quality Index & -0.431 & $<0.001$ & 0.650 & 0.612 & 0.90 \\
Physical Activity & -0.118 & $<0.001$ & 0.889 & 0.845 & 0.933 \\
Usage of Electronic Devices & 0.064 & 0.014 & 1.066 & 1.013 & 1.121 \\
Nutrition & -0.142 & $<0.001$ & 0.868 & 0.864 & 0.908 \\
Smoking (no as a control) & & & & & \\
$\quad$ Yes & 0.601 & 0.005 & 1.824 & 1.195 & 2.755 \\
Drinking (no as a control) & & & & & \\
$\quad$ Yes & -0.034 & 0.735 & 0.966 & 0.792 & 1.177 \\
Losing Weight (no as a control) & & & & \\
$\quad$ Yes & 0.227 & 0.016 & 1.255 & 1.043 & 1.509 \\
\hline
\end{tabular}

classified with SHS. Students who take part in less physical activity were more likely to be included in the SHS group. And students who spend more time on electronic devices were more likely to be categorized with SHS. Additionally, smoking was a risk factor of SHS, and the students with lower scores in nutrition were more likely to be grouped into SHS. Students who had lost weight were also more likely to be classified as having SHS.

\section{Discussion}

The main purpose of this study is to better understand current situations of suboptimal health status in college freshmen and the factors affecting the health status of university students, with a particular emphasis on exploring the impact of electronic product usage on SHS. In our study, we found that the prevalence rate of SHS was $47.6 \%(2481 / 5344)$. This result is similar to those of other studies conducted in China [10, 14]. Although the prevalence of SHS is high, there has not objective clinical diagnostics for SHS so far. A number of SHS questionnaires have been established and evaluated in China, including the Multidimensional Sub-Health Questionnaire of Adolescents (MSQA) which is aimed at adolescents and the Suboptimal Health Status Questionnaire-25 (SHSQ-25) which is targeted at physiological and psychological SHS [34, 35]. The SHMS V1.0, which we used in our study, is a standardized questionnaire [33] used to assess respondents' health status, and it contains a multidimensional, self-report symptom inventory. As freshmen enter a university, a number of students may have some physical, psychological, and social problems. Hence, for assessing the overall health status of students, the SHMS V1.0 is a suitable scale.

In our study, we found that some social demographic characteristics were associated with health status, such as age and area (Table 4). More students aged 1519 years old were classified with SHS than those aged 20-24 years old. This result is not consistent with other studies, which found that younger adolescents had better health statuses [36]. We believe the main reason for this is that most of the students in the 15- to 19-year-old age group have just taken the college entrance examination. They've suffered from huge pressure to get good scores in order to enter an excellent college. Many students will sit and study all day, seldom going outdoors to exercise and sometimes paying no attention to their daily diet and nutrition, which results in harm to their health. We also found that students from rural areas had higher rates of SHS than those from urban areas. Students from rural areas often find that living environments when they enter college, usually located in a big city, are much different from those of their hometowns. They have to adapt in a short period of time and are more easily influenced by academic pressure or peer pressure, which could make them more prone to developing SHS [37].

We also found that some lifestyle behaviors were associated with health status, such as sleep quality, physical activity, the use of electronic equipment, nutrition, and losing weight. Poor sleep quality is positively associated with SHS. According to existing research, most young people need nine hours of restful sleep each night [38]. However, for a number of reasons, many school-aged children often get less than the recommended number of hours of sleep. Sleep quality has important implications for cognitive outcomes, mental health, physical health, work performance, and safety [39]. A mental health survey conducted by $\mathrm{Gu}$ et al. of 11,618 residents aged 18 years or older revealed that the rate of poor sleep quality in residents with mental disorders was 6.51 times higher than that of those without mental disorders [40]. Sleep-deprived individuals suffer from negative moods [41], are more likely to experience distress [42], are more likely to experience obesity [43], and are at a greater risk for coronary heart disease [44]. So poor sleep quality tends to lead to SHS.

Much existing evidence suggests that physical activity is associated with numerous health benefits [45, 46]. In general, the association of physical activity with mental health in young people is evident [47]. It has also been demonstrated that physical activity can influence the mental health of college students [48]. Our study found 
a significant relationship between low physical activity and SHS among college freshmen. Thus, it can be said that increased physical activity is helpful for college students, whose brains are highly plastic [49]. Possible mechanisms include an increase in serotonin or other neurotransmitters associated with the "endorphin effect" of alleviating negative feelings.

One main purpose of our study is to explore the relationship between electronic device usage and SHS. We found that overusing electronic equipment was positively associated with SHS. Electronic devices are ubiquitous among modern youth and are frequently used. Most students use electronic equipment to surf the Internet, and the negative impacts of uncontrolled Internet use have been a source of concern among researchers. Internet overuse has, in fact, been found to have negative impacts on psychological well-being, as well as social, occupational, academic, marital, and interpersonal relations [26, 50]. The EPIC Norfolk study showed that each 1-h/day increase in TV time was associated with increased hazard of all-cause and cardiovascular [51]. A dose response relationship was found between time using electronic equipment and psychological symptoms like poor appetite, loneliness, sleeping difficulties, sadness and hopelessness [52]. A study of 4747 college students in 2013 found that high screen time was associated with increased risks of mental health problems [53]. A similar relationship was also reported for neurological symptoms like dizziness, tremors, headache and stomach aches [54]. The studies above show the strong relationship between electronic equipment and health. Possible underlying mechanisms for the adverse health effects are complex. One of the ways that using electronic equipment has been hypothesized to influence health is by displacing time that could otherwise have been used for physical activity [51]. Another possible reason is that overusing electronic equipment is highly correlated with increased metabolic risk [55], and metabolic risk is associated with poor health [56]. So it can be said that more moderate use of electronic devices can improve the health status of college students.

We further found that poor nutrition status was associated with SHS among college freshmen. Many studies have previously found that poor nutrition status can seriously damage health $[14,17]$. Chen et al. conducted a cross-sectional survey within a clustered sample of 24,159 individuals aged 12-80 years old during 2012-2013 in southern China [14]. This survey found that irregular breakfast-eating habits were related to an increased risk of SHS, and increased breakfast-eating frequency could contribute to lowering the prevalence of SHS in southern China. In our study, we found that losing weight was also highly correlated with SHS. Many students, especially girls, utilized diet pills, excessive dieting, and/or fasting to lose weight. A health survey conducted among 1629 students in 2009 found that unhealthy weightreducing behavior was the main risk factor for SHS [57]. Previous studies have shown that insulin sensitivity can be reduced in response to pre-loading through excessive dieting, thus disturbing lipid profiles [58]. Further, excessive dieting and fasting can lead to deleterious metabolic and endocrine-related variation via the disruption of daily energy intake and upregulation of appetite. [59]. And weight loss over the long term can lead to malnutrition, which is harmful to one's health. So emphasizing good nutrition status and healthy weight-reducing behaviors will benefit college students in terms of their health status.

SHS is an intermediate state between disease and health and is often medically undiagnosed. Students with diseases may worry about their health status and take some approaches to improve their symptoms, such as changing their poor lifestyle behaviors. SHS students, on the other hand, usually are not diagnosed. So they do not pay attention to their lifestyle behaviors, which leads to continuing health loss. Therefore, it is important to focus attention on SHS and lifestyle factors that threaten the health of young people. Prevention and intervention strategies aimed at SHS are effective approaches to improve health outcomes, the prevention of diseases, and the treatment of early-stage illnesses.

\section{Limitations}

Some limitations for this study should be noted. First, this was a cross-sectional survey, which did not allow us to assess causality or the directionality of relationships. Second, all information was obtained from self-reported questionnaires, which could result in potential information bias. Also, we could not get some information, such as genetics, economic status, and so on which may be associated with SHS. Third, although the presence of poor sleep quality as well as suboptimal health status were assessed by standardized questionnaires, these measures are not equivalent to clinical diagnoses, thus future studies with diagnostic interviews should be used. Finally, the results may not represent all Chinese young adults, because all the participants who were general healthy and well-educated came from one large Chinese university and there was a big gender difference with $65 \%$ female which is higher than statistical data (52.11\%) from Ministry of Education of the People's Republic of China [60]. 


\section{Conclusion}

Through this research into Chinese college freshmen, we found that poor lifestyle behaviors were significantly positively associated with SHS. In particular, the overuse of electronic devices is one of underlying causes of SHS. Focusing on these lifestyle factors, actions were recommended to improve the health status of this population.

\section{Additional file}

Additional file 1: English copy of the questionnaire. (DOCX 24 kb)

\section{Abbreviations}

CACM: China Association of Chinese Medicine; Cls: Confidence intervals: HPLP: Health Promoting Lifestyle Profile; HPLS: Health promotion lifestyle scale; OR: Odds ratios; SHMS V1.0: Suboptimal Health Measurement ScaleV1.0; SHS: Suboptimal health status; SQI: Sleep quality index; WHO: World Health Organization

\section{Acknowledgments}

We would like to thank all survey staff and students at the School of Statistics and the Hospital of Renmin University of China.

\section{Funding}

This work was supported by the Fundamental Research Funds for the Central Universities, and the Research Funds of Renmin University of China (16XNI008).

\section{Availability of data and materials}

The datasets generated and/or analyzed during the current study are not publicly available due to protect the students' privacy, but are available from the corresponding author on reasonable request.

\section{Authors' contributions}

YW and WX designed the study. YW, WX, CM, LZ and SM designed the survey. CM and LZ conducted data analysis. YW drafted the manuscript with input from the other authors. All authors read and approved the final version of the manuscript.

\section{Ethics approval and consent to participate}

The study was approved by the ethics committee of Renmin University. Each interviewee was asked to sign an informed consent form. An interviewee was excluded if he/she refused to participate.

\section{Consent for publication}

Not applicable.

\section{Competing interests}

The authors declare that they have no competing interests.

\section{Publisher's Note}

Springer Nature remains neutral with regard to jurisdictional claims in published maps and institutional affiliations.

\section{Author details}

${ }^{1}$ Center for Applied Statistics and School of Statistics, Renmin University of China, Beijing, China. ${ }^{2}$ School of Public Health, Yale University, New Haven, $\mathrm{CT}$, USA.

Received: 8 March 2017 Accepted: 20 December 2017 Published online: 05 January 2018

\section{References}

1. Grad FP. The preamble of the constitution of the World Health Organization. Bull World Health Organ. 2002;80(12):981-4.

2. World Health Organization. Health systems strengthening glossary. http:// www.who.int/healthsystems/Glossary_January2011.pdf. Accessed 1 Mar 2007.
3. Wang W, Yan Y. Suboptimal health: a new health dimension for translational medicine. Clin Transl Med. 2012;1(1):28. https://doi.org/10.1186/ 2001-1326-1-28

4. Schaefert R, Hausteiner WC, Hauser W, Ronel J, Herrmann M, Henningsen P. Treatment of non-specific, functional and somatoform bodily complaints. Dtsch Med Wochenschr. 2014;139(12):602-7.

5. Schmid G, Dinkel A, Henningsen P, Dieterich M, Hopfner A, Pieh C, et al. Assessment of psychological aspects of somatoform disorders: a study on the German version of the health attitude survey (HAS). Compr Psychiatry. 2014;55(1):155-64

6. Henningsen P, Zipfel S, Herzog W. Management of functional somatic syndromes. Lancet. 2007;369(9565):946-55. https://doi.org/10.1016/s01406736(07)60159-7.

7. Wang W, Russell A, Yan Y. Traditional Chinese medicine and new concepts of predictive, preventive and personalized medicine in diagnosis and treatment of suboptimal health. EPMA J. 2014;5(1):4.

8. Dunstan RH, Sparkes DL, Roberts TK, Crompton MJ, Gottfries J, Dascombe BJ. Development of a complex amino acid supplement, fatigue Reviva, for oral ingestion: initial evaluations of product concept and impact on symptoms of sub-health in a group of males. Nutr J. 2013;12:115. https:// doi.org/10.1186/1475-2891-12-115.

9. Davy CP, Patrickson M. Implementation of evidence-based healthcare in Papua New Guinea. Int J Evid Based Healthc. 2012;10(4):361-8.

10. Bi J, Huang Y, Xiao Y, Cheng J, Li F, Wang T, et al. Association of lifestyle factors and suboptimal health status: a cross-sectional study of Chinese students. BMJ Open. 2014;4(6):e005156.

11. Liang Q, Zeng T, Li Q, Yi Y, Huang J, Wei L, et al. Investigation on composition factor and risk factors of sub-health among residents in Guangzhou. Mod Prev Med. 2013;07:1294-8.

12. Yan Y, Liu Y, Li M, Hu P, Guo A, Yang $X$, et al. Development and evaluation of a questionnaire for measuring suboptimal health status in urban Chinese. J Epidemiol. 2009:19(6):333-41. https://doi.org/10.2188/jea.JE20080086.

13. Zhao X, Zhu W, Zhang C, Yang L. Assessment on sub-health condition of doctors of municipal hospitals in Zhengzhou. J Zhengzhou Univ. 2011;46(3):436-9.

14. Chen JY, Cheng JR, Liu YY, Tang Y, Sun XM, Wang T, et al. Associations between breakfast eating habits and health-promoting lifestyle, suboptimal health status in southern China: a population based, cross sectional study. J Transl Med. 2014;12:348. https://doi.org/10.1186/s12967-014-0348-1.

15. Liu Z, Li M. The third state and psychosomatic medicine research. Med Philosophy. 2001;22(1):36-8.

16. Çoban A, O K, Özbasaran F. The evaluation of school of health students' knowledge and behavior of healthy life-styles of related to importance to prevent cancer. Asian Pac J Cancer Prev. 2010;11(3):773-6.

17. Maksimovic MZ, Gudelj JM, Vlajinac HD, Vasiljevic ND, Marinkovic JM. Relationship between health behaviour and body mass index in the Serbian adult population: data from National Health Survey 2013. Int J Public Health. 2016;61(1):57-68. https://doi.org/10.1007/s00038-015-0765-9.

18. Gooding HC, Shay CM, Ning H, Gillman MW, Chiuve SE, Reis JP, et al. Optimal lifestyle components in young adulthood are associated with maintaining the ideal cardiovascular health profile into middle age. J Am Heart Assoc. 2015;4(11):e002048. https://doi.org/10.1161/JAHA.115.002048.

19. Takeshita T, Morimoto K. Effects of lifestyle on health status. Rinsho Byori. 1995;43(11):1087-94

20. Yao YS, Wang LH, Chen Y, Kang YW, QJ G, Fang WH, et al. Correlation analysis of anxiety status and sub-health status among students of 13-26 years old. Int J Clin Exp Med. 2015;8(6):9810-4.

21. Xu J, Feng LY, Luo R, Qiu JC, Zhang JH, Zhao XS, et al. Assessment of the reliability and validity of the sub-health measurement scale Version1.0. J South Med Univ. 2011;31(1):33-8.

22. Zhou Y, You LM, Zhang JB, Guan NH. Causes and prevention of sub-health. Chinese Journal of Health Education. 2002;12:714-5.

23. Pokhrel P, Little MA, Herzog TA. Current methods in health behavior research among U.S. community college students: a review of the literature. Eval Health Prof. 2014;37(2):178-202.

24. Berg CJ, An LC, Thomas JL, Lust KA, Sanem JR, Swan DW, Ahluwalia JS. Smoking patterns, attitudes and motives: unique characteristics among 2year versus 4-year college students. Health Educ Res. 2011;26(4):614-23.

25. Peltzer K, Pengpid S, Mohan K. Prevalence of health behaviors and their associated factors among a sample of university students in India. Int J Adolesc Med Health. 2014;26(4):531-40. 
26. Yao B, Han W, Zeng L, Guo X. Freshman year mental health symptoms and level of adaptation as predictors of internet addiction: a retrospective nested case-control study of male Chinese college students. Psychiatry Res. 2013;210(2):541-7.

27. Teng HL, Yen M, Fetzer S. Health promotion lifestyle profile-II: Chinese version short form. J Adv Nurs. 2010;66(8):1864-73.

28. Carlson EDA. Case study in translation methodology using the healthpromotion lifestyle profile II. Public Health Nurs. 2000;17(1):61-70.

29. Hulme PA, Walker SN, Effle KJ, Jorgensen L, McGowan MG, Nelson JD, et al. Health-promoting lifestyle behaviors of Spanish-speaking Hispanic adults. J Transcult Nurs. 2003;14(3):244-54.

30. Buysse DJ, Hall ML, Strollo PJ, Kamarck TW, Owens J, Lee L, et al. Relationships between the pittsburgh sleep quality index (PSQI), epworth sleepiness scale (ESS), and clinical/polysomnographic measures in a community sample. J Clin Sleep Med. 2008;4(6):563-71.

31. Buysse DJ, Reynolds CF, Monk TH, Berman SR, Kupfer DJ. The pittsburgh sleep quality index: a new instrument for psychiatric practice and research. Psychiatry Res. 1989;28(2):193-213.

32. Buysse DJ, Reynolds CF, Monk TH, Hoch CC, Yeager AL, Kupfer DJ. Quantification of subjective sleep quality in healthy elderly men and women using the Pittsburgh sleep quality index (PSQI). Sleep. 1991;14(4):331-8.

33. Medicine CAOC. The TCM clinical guidelines of suboptimal health status. Beijing: China Press TCM; 2006.

34. Wang $\mathrm{H}$, Li L, Xu H. Evaluation Of the multidimensional sub-health questionnaire of adolescents. Chinese General Practice. 2011;14(25):2933-6.

35. Yan Y, Dong J, Liu Y, Yang X, Li M, Shia G, et al. Association of suboptimal health status and cardiovascular risk factors in urban Chinese workers. J Urban Health. 2012;89(2):329-38.

36. Bolton K, Kremer P, Rossthorn N, Moodie M, Gibbs L, Waters E, et al. The effect of gender and age on the association between weight status and health-related quality of life in Australian adolescents. BMC Public Health. 2014;14:898. https://doi.org/10.1186/1471-2458-14-898.

37. Nauman $E$, VanLandingham $M$, Anglewicz $P$, Patthavanit $U$, Punpuing $S$. Rural-to-urban migration and changes in health among young adults in Thailand. Demography. 2015;52(1):233-57. https://doi.org/10.1007/s13524014-0365-y.

38. HOSFS C. Hours of sleep for school children. Journal of the American Medical Association. 1905; xlv(19):1410.

39. Barnes CM, Drake CL. Prioritizing sleep health: public health policy recommendations. Perspectives on psychological science. a journal of the Perspect Psychol Sci. 2015;10(6):733-7. https://doi.org/10.1177/1745691615598509.

40. Gu Y, Xu GM, Yin HF. Epidemiologic study on sleep quality of community population aged 18 years or over in Tianjin. Chin Mental Health J. 2015;3: 199-203.

41. Dinges DF, Pack F, Williams K, Gillen KA, Powell JW, Ott GE, et al. Cumulative sleepiness, mood disturbance, and psychomotor vigilance performance decrements during a week of sleep restricted to 4-5 hours per night. Sleep. 1997;20(4):267-77.

42. Glozier N, Martiniuk A, Patton G, Ivers R, Li Q, Hickie I, et al. Short sleep duration in prevalent and persistent psychological distress in young adults: the DRIVE study. Sleep. 2010;33(9):1139-45.

43. Taheri $S$, Ling $L$, Diane A, Terry $Y$, Emmanuel $M$. Short sleep duration is associated with reduced leptin, elevated ghrelin, and increased body mass index. PLoS Med. 2004;1(3):e62.

44. Ayas NT, White DP, Manson JE, Stampfer MJ, Speizer FE, Malhotra A, et al. A prospective study of sleep duration and coronary heart disease in women. Arch Intern Med. 2003;163(2):205-9.

45. Xu J, Wei Y. Social support as a moderator of the relationship between anxiety and depression: an empirical study with adult survivors of Wenchuan earthquake. PLoS One. 2013;8(10):e79045. https://doi.org/10. 1371/journal.pone.0079045.

46. Stein C, Fisher L, Berkey C, Colditz G. Adolescent physical activity and perceived competence: does change in activity level impact selfperception? J Adolesc Health. 2007;40(5):462.e1-8.

47. Biddle SJ, Asare M. Physical activity and mental health in children and adolescents: a review of reviews. Br J Sports Med. 2011;45(11):886-95.

48. Adams TB, Moore MT, Dye J. The relationship between physical activity and mental health in a national sample of college females. Women Health. 2007:45(1):69-85.

49. Ploughman M. Exercise is brain food: the effects of physical activity on cognitive function. Dev Neurorehabil. 2008;11(3):236-40. https://doi.org/10. 1080/17518420801997007.
50. Krauft R, Michael P, VickiKiesler L, Mukopadhayay S, William TS. Internet paradox: a social technology that reduces social involvement and psychological well-being? Am Psychol. 1998;53(9):1017-31.

51. Wijndaele K, Brage S, Besson H, Kaytee K, Sharp SJ, Luben R, et al. Television viewing time independently predicts all-cause and cardiovascular mortality: the EPIC Norfolk study. Int J Epidemiol. 2011;40(1):150-9.

52. Yang F, Helgason AR, Sigfusdottir ID, Kristjansson AL. Electronic screen use and mental well-being of 10-12 year-old children. Eur J Pub Health. 2013 Jun;23(3):492-8.

53. Wu X, Tao S, Zhang Y, Zhang S, Tao F. Low physical activity and high screen time can increase the risks of mental health problems and poor sleep quality among Chinese college students. PLoS One. 2015;10(3):e0119607. https://doi.org/10.1371/journal.pone.0119607.

54. Taehtinen RE, Sigfusdottir ID, Helgason AR, Kristjansson AL. Electronic screen use and selected somatic symptoms in 10-12 year old children. Prev Med 2014 Oct; 67:128-133. doi: https://doi.org/10.1016/j.ypmed.2014.07.017. Epub 2014 Jul 19

55. Melkevik O, Torsheim T, lannotti RJ, Wold B. Is spending time in screenbased sedentary behaviors associated with less physical activity: a cross national investigation. Int J Behav Nutr Phys Act. 2010;7:46. https://doi.org/ 10.1186/1479-5868-7-46

56. Goldbacher EM, Matthews KA. Are psychological characteristics related to risk of the metabolic syndrome? A review of the literature. Ann Behav Med. 2007;34(3):240-52. https://doi.org/10.1080/08836610701677212.

57. Fang Q, Wang H, LI L. Sub-health status and behavioral risk factors among middle school students in three gorges area, Chongqing. Chin J Public Health. 2013;29(1):94-6.

58. Astbury NM, Taylor MA, Macdonald IA. Breakfast consumption affects appetite, energy intake, and the metabolic and endocrine responses to foods consumed later in the day in male habitual breakfast eaters. J Nutr. 2011;141(7):1381-9.

59. Farshchi HR, Taylor MA, Macdonald IA. Beneficial metabolic effects of regular meal frequency on dietary thermogenesis, insulin sensitivity, and fasting lipid profiles in healthy obese women. Am J Clin Nutr. 2005;81(1):16-24.

60. Number of Female Students of Schools by Type and Level in 2015. Ministry of Education of the People's Republic of China 2015 http://www.moe.gov. cn/s78/A03/moe_560/jytjsj_2015/2015_qg/201610/t20161012_284506.html.

\section{Submit your next manuscript to BioMed Central and we will help you at every step:}

- We accept pre-submission inquiries

- Our selector tool helps you to find the most relevant journal

- We provide round the clock customer support

- Convenient online submission

- Thorough peer review

- Inclusion in PubMed and all major indexing services

- Maximum visibility for your research

Submit your manuscript at www.biomedcentral.com/submit 